Achieving Sustainable New Happiness:

Prospects, Practices, and Prescriptions

\author{
Kennon M. Sheldon \\ University of Missouri-Columbia
}

\author{
Sonja Lyubomirsky \\ University of California, Riverside
}

Reference: Sheldon, K. M., \& Lyubomirsky, S. (2004). Achieving sustainable new happiness:

Prospects, practices, and prescriptions. In A. Linley \& S. Joseph (Eds.), Positive psychology in practice (pp. 127-145). Hoboken, NJ: John Wiley \& Sons. 


\section{Achieving Sustainable New Happiness: Prospects, Practices, and Prescriptions}

"Happiness depends upon ourselves." - Aristotle

"It is not God's will merely that we should be happy, but that we should make ourselves happy." - Immanuel Kant

"Like swimming, riding, writing, or playing golf, happiness can be learned." - Boris Sokoloff

Happiness is a central criterion of mental health (Jahoda, 1958; Taylor \& Brown, 1988) and has been found to be associated with numerous tangible benefits, such as enhanced physical health, reduced psychopathology, superior coping skills, and even longer life (see Lyubomirsky, King, \& Diener, 2003, for a review). Thus, an important goal for positive psychology is advancing knowledge about how to help people increase their levels of happiness, positive mental health, and personal thriving. As numerous commentators have noted (Seligman \& Csikszentmihalyi, 2000; Sheldon \& King, 2001), this issue has received very little research attention, as mental health interventions have primarily focused on ameliorating suffering, weakness, and anxiety, rather than on increasing happiness and well-being. The assumption of such interventions appears to be that if we can relieve a person's suffering, then well-being will result. However, this reasoning appears to be erroneous - that is, relieving people's suffering may only return them "back to zero" and do nothing to help them achieve their optimum happiness potentials.

How, then is it possible to help people go beyond zero, beyond the hedonic "neutral" point - that is, to lift them and sustain them above this point, thereby helping them attain their highest possible levels of happiness? Immediately, we encounter a paradox: Perhaps it is not possible at all! Indeed, some contemporary theories of well-being seem to indicate that trying to increase one's happiness levels is futile - an endeavor doomed from the start. As described below, this pessimism is rooted in several assumptions about the nature of psychological well-being, including the notion of a genetic set point for happiness, the concept of hedonic adaptation, and the idea that there is much longitudinal stability for well-being-related personality traits. All of these views imply that, although people might become happier or more satisfied in the short term, they are 
destined to return to their original level in the long term. If this is so, then perhaps people should give up on the idea of becoming happier!

In this chapter, we will first consider the idea that it is impossible to sustainably increase one's level of well-being. Then, we will present some evidence suggesting that there may be reason for hope after all. To illustrate, we will next present our own formal model of sustainable gains in well-being, which focuses on the distinction between the genetic set point, the positive circumstantial changes that a person undergoes, and the positive activity changes that a person enacts. We will try to show that sustainable gains in well-being are indeed possible, if the person makes the "right kind" of changes in his/her life (i.e., activity changes), and we will describe some new data to support this proposition. We will then consider some specific types of volitional or activity changes that a person might make, such as resolving to regularly count one's blessings, pursue meaningful personal goals, or commit random acts of kindness. In the final part of the chapter, we will discuss how to best frame and conduct such interventions, so that they have the best chance of success.

\section{Why It May Be Impossible To Increase One's Happiness Level}

Considerable behavioral-genetic research indicates that permanently changing one's happiness levels is very difficult, if not impossible. In other words, it appears there is a genetically-determined set point for happiness. Indeed, Lykken and Tellegen (1996) provided twin and adoption data to suggest that the heritability of well-being may be as high as $80 \%$ (although a more widely accepted figure is 50\%; Braungart, Plomin, DeFries, \& Fulker, 1992; Tellegen et al., 1988; cf. Diener, Suh, Lucas, \& Smith, 1999). This suggests that each person has a built-in "attractor" for happiness, which he or she can orbit around, but never leave behind (Vallacher \& Nowak, 2002). In other words, the set point remains the most likely or expected value in a person's temporal distribution of happiness across the life span. Consistent with this idea, Headey and Wearing (1989) found, in a 4-wave panel study, that participants tended to keep returning to their own baselines over time (see also Suh, Diener, \& Fujita, 1996).

A related source of pessimism comes from research on personality traits. Traits are cognitive, affective, and behavioral complexes that are, by definition, consistent across situations 
and across the lifespan (Allport, 1955). Therefore, they may account for part of the stability of well-being. For example, McCrae and Costa (1990) have shown impressive long-term stability for neuroticism and extraversion, the two "Big Five" traits most closely related to well-being. Based on such data, McCrae and Costa argued that people also tend to maintain the same relative level of happiness over time (see also Costa, McCrae, \& Zonderman, 1987; Diener \& Lucas, 1999).

A third source of pessimism arises from the concept of hedonic adaptation (Frederick \& Loewenstein, 1999) or the hedonic treadmill (Brickman \& Campbell, 1971). Humans quickly adapt to changes, positive or negative (Kahneman, 1999; Scitovsky, 1976; Tversky \& Griffin, 1991). Thus, although new circumstances may temporarily cause people to become happier or sadder, the effect of these new circumstances on happiness diminishes quickly or even disappears entirely, once people habituate to it. In support of this idea, Brickman, Coates, and JanoffBulmann (1978) showed that after one year, lottery winners were no happier than controls and recent paralysis victims were not as unhappy as one would expect. The notion of habituation brings to mind the image of a person walking up a descending escalator; although the improving circumstances of her life may propel her upward towards greater happiness, the process of adaptation eventually forces her back to her initial state.

These three ideas all suggest that "what goes up must come down." If so, then instead of seeking an upward spiral, perhaps people would be better off simply accepting their current personality and happiness levels (McCrae \& Costa, 1994). By doing so, they might avoid experiencing upsetting fluctuations and instabilities in their mood and self-feelings (Kernis, Brown, \& Brody, 2000), and the disappointment of realizing that nothing really makes a difference (Gaskins, 1999).

Why It May Be Possible To Increase One's Happiness Level After All

If the above considerations are true, then the very linchpin of the American ideology (and Western ideology more generally) - namely, that one can take action to pursue and attain new happiness - becomes suspect. These considerations also have troubling implications for the positive psychology movement, and its avowed goal of enhancing personal and social well-being. However, we believe that the above arguments are over-stated, and that most people have 
considerable "room for improvement" in their chronic levels of happiness. We outline the counterarguments below.

First, some researchers have had success in using interventions to increase happiness (e.g., Fava, Rafanelli, Cazzaro, Conti, \& Grandi, 1998; Fordyce, 1977, 1983; Langer \& Rodin, 1976; Lichter, Haye, \& Kammann, 1980; Sheldon, Kasser, Smith, \& Share, 2002). Indeed, recent research in the positive psychology tradition has identified several promising interventions, including prompting participants to pursue meaningful personal goals (Sheldon \& Elliot, 1999), to seek out and forgive transgressors (McCullough, Pargament, \& Thoresen, 2000), and to count their blessings on a regular basis (Emmons \& McCullough, 2003). Notably, however, most of this research has not examined the stability of these changes in the long-term.

Second, research documenting the long-term effectiveness of cognitive and behavioral strategies to ameliorate negative affect and depression has encouraging implications for the possibility of elevating long-term happiness (Gillham \& Reivich, 1999; Gloaguen, Cottraux, Cucherat, \& Blackburn, 1998; Jacobson et al., 1996). Furthermore, evidence that psychotherapeutic outcomes can be stable in the long-term supports the idea that gains in happiness might also be stable.

Another reason why genes are not necessarily destiny is that they influence happiness only indirectly - i.e., by shaping the kinds of experiences and environments one has or seeks to have. Thus, unwanted effects of genes could be minimized by active efforts to steer oneself away from problematic situations or to avoid maladaptive behaviors (Lykken, 2000). In addition, it is worth noting that heritability coefficients describe co-variations, not mean levels. Thus, even a high heritability coefficient for a particular trait (such as happiness) does not rule out the possibility that the mean level of that trait for a specific population can be elevated. Under the right conditions, everyone might become happier than they were before, even if their rank ordering relative to others remains stable.

Finally, recent longitudinal investigations of personal goal-pursuit suggest that happiness may be sustainably boosted. For example, Sheldon and Houser-Marko (2001) conducted a 4-wave study of college freshmen, covering the entire first academic year. They showed that students who 
well-attained their goals over the first semester experienced an increase in their global well-being scores. Although some of these students had regressed back to their original starting point by the end of the second semester, other students maintained their earlier gain - specifically, those who continued to do very well in their personal goals during the second semester. Thus, consistent with our theoretical model, these results suggest that new (in this case, goal-based) activities can first boost well-being, and then maintain it at the new level, to the extent that the person remains successful in the activities. More recently, Sheldon and Lyubomirsky (2003) re-visited this "freshman goals" sample at the end of their senior year, and found that the doubly-successful group had maintained their initial gain throughout their entire college career. Presumably, their initially successful activity instigated a cascading series of positive experiences throughout their undergraduate years.

\section{A New Conceptual Model Of Happiness}

Which of these perspectives is true? Are sustainable gains in well-being possible, or are they impossible? The fact is, we simply do not know. Indeed, there has been a remarkable paucity of longitudinal research on happiness. Instead, most of the existing literature concerns the cross-sectional associations of various factors (such as income, gender, traits, attitudes, and goals) with concurrent well-being. In other words, most well-being research focuses on between-subject (cross-person) differences, rather than within-subject (cross-time) differences. While this may be due in part to the difficulty of conducting longitudinal studies, we believe part of it is rooted in the considerable scientific pessimism, described above, over whether sustainable happiness increases are possible. The assumption seems to have been that because lasting within-subject variations are impossible, between-subject variations tell us all we need to know.

In contrast to this view, our model (Sheldon, Lyubomirsky, \& Schkade, 2003), described below, focuses explicitly on within-subject variations, making the assumption that it is indeed possible to achieve, and maintain, a level of happiness greater than one's set point. Before turning to the model, we first offer a conceptual definition of happiness. 


\section{Definition of Happiness}

Happiness is defined here as it is often defined empirically - that is, via people's direct ratings of their happiness, long-term balance of positive and negative affect, or life-satisfaction (Diener, 1984; Lyubomirsky, 2001). Notably, these terms are not readily separable (Lyubomirsky \& Lepper, 1999; Stones \& Kozma, 1985), and thus we use them interchangeably in this chapter. Because all three constructs are inherently subjective, they are usually assessed via self-report. Although this may be construed as a methodological weakness, we believe it essential to rely on an individual's own perspective. Indeed, it would make little sense to pronounce a particular person as happy unless he thought so himself.

Our primary focus in this article is on a person's characteristic level of happiness during a particular period in his or her life, which we term the current happiness level. We define happiness this way because we wish to identify a quantity that is more enduring than momentary or daily happiness, but that is also somewhat malleable over time, and thus amenable to meaningful pursuit. Operationally, one might define a person's current happiness level in terms of his or her retrospective summary judgments regarding some recent period (such as the last 2, 6, or 12 months), or as the average of momentary judgments of happiness generated at multiple times during that period.

\section{Determinants of Happiness}

Our model identifies three primary factors that influence a person's current happiness level: The happiness set point, circumstantial/contextual factors in the person's life, and volitional/activity-based factors in the person's life (see Figure 1).

Set point. The set point is genetically determined and essentially constant. In a sense, it represents the level of happiness a person is likely to experience when all other factors in the model are equal to zero. In other words, the set point is analogous to the intercept in a withinsubject regression equation, a constant which always contributes to the output value, and which determines it exactly when the other factors in the model have no influence or have canceling influences. 
The regression equation metaphor suggests an interesting possibility - that the set point it is not really a set point, but rather, a set range. That is, people may have considerable latitude to be located above the central point, depending on the other factors in the model. An analogy is provided by an example involving the intelligence quotient (IQ): Although an average individual's potential range of IQ may be largely determined at birth (i.e., between 85 and 115), exactly where she ends up in her range may depend on other factors. In a stimulating and nurturing environment, the child may achieve an IQ near the top of her potential (e.g., 112), and in a non-supportive environment, she may instead inhabit the bottom of her potential range (e.g., 87).

Of course, happiness is not really like IQ, which is largely rooted in cognitive development. Because achieved cognitive abilities are unlikely to be lost (except in the case of disease or advanced age), high IQ, once attained, is not likely to be lost. In contrast, happiness may be inherently more unstable than IQ, such that high levels relative to the set point may not be maintainable. Again, however, we believe this argument over-states the case. To illustrate, it is necessary to consider the critical differences between life-circumstances and life-activities.

Circumstances. According to our model, positive life-changes relevant to happiness fall into two broad categories - those based on changes in the circumstances, settings, and facts of one's life, and those based on changes in one's intentional activities in life. "Circumstances" refers to demographic variables, such as age, marital status, employment status, and income. They also refer to geographic and contextual variables, such as the home and region in which one lives, the conveniences one enjoys, and the possessions one has. All of these examples share an important feature in common - they tend to remain relatively static and stable, becoming part of the "background" of the person's life or, as Henry James (1909) eloquently put it, "the whole envelope of circumstance." Our model assumes that people relatively quickly adapt to positive circumstantial changes precisely because of their static character.

According to this view, one's new flat screen television, one's relocation to California, or one's new income level may all give one a temporary boost, but the boost will likely fade after one habituates to the constant new situation. Another way of illustrating this notion is to state that a within-subject regression equation such as that described above would need to include a "time 
elapsed" variable as a moderator of the effect of circumstantial changes. That is, the more time that has gone by since the new circumstance arose, the smaller influence the circumstance would be expected to have on the predicted level of well-being at a particular point in time. Again, Headey and Wearing's (1989) 4-wave panel study of the transitory influence of life circumstances on changes in well-being supports this idea, as do Brickman and colleagues' (1978) findings regarding the fleeting effects of winning the lottery.

Intentional activities. In contrast, "activities" refer to the intentional and effortful practices in which a person engages. Such practices may be cognitive (i.e., one regularly adopts an optimistic or positive attitude), behavioral (i.e., one is regularly kind to others or regularly engages in physical exercise), or volitional (i.e., one identifies and strives for meaningful personal goals). Common to all of these is the notion of intentional effort and commitment in service of particular desired objectives or experiences.

Because of their intentional character, activities are more resistant to the effects of adaptation. In other words, one can deliberately vary one's activities, such that they continually provide new experiences and results. Indeed, some intentional activities (such as meditation, or pausing to count one's blessings) can serve to directly counter adaptation. Furthermore, intentional activity can create a self-sustaining cycle of positive change, in which invested effort leads the person to further opportunities for satisfying actions and accomplishments. Of course, one can also perform an activity robotically, without variation, or can fail to sensitively apply or enact the strategy. In such cases (described in more detail below), the benefits of the activity are likely to fade over time, just as the impact of positive circumstantial changes dampens. Still, activities have the potential to create sustained positive change, because of their more dynamic and varying nature and because of their capacity to produce a steady stream of positive and rich experiences. If anything can do it, activities can!

Of course, the boundary between activity changes and circumstantial changes is somewhat fuzzy. For example, bringing about many circumstantial changes undoubtedly takes intentional effort, and, conversely, circumstantial changes may enable or afford new types of activity. Furthermore, some kinds of circumstances (i.e., the demographic factor of marital status) doubtless 
involve activity (i.e., one acts within the marital relationship). Nevertheless, the data we will describe below suggests that the basic distinction between the two types of factors is meaningful and important.

\section{Testing the Model}

Sheldon and Lyubomirsky (2003) recently conducted a three-wave longitudinal study of 666 undergraduates. Students rated their well-being at the beginning of an academic semester, using a variety of standard measures. Midway through the semester, they rated the extent to which they had experienced both positive activity and positive circumstantial changes since the beginning of the semester, and also rated their well-being again. They then rated their well-being a final time at the end of the semester. Sheldon and Lyubomirsky (2003) predicted that both positive activity changes and positive circumstantial changes would predict enhanced well-being from Time 1 to Time 2, but that only activity changes would predict maintained gains at Time 3 .

The activity and circumstance measures each consisted of a single item, with which participants rated their agreement. The circumstances item read: "Please rate the extent to which there has been some significant positive change in the circumstances of your life since the beginning of the semester, which has given you a boost since it occurred. 'Circumstances' means 'facts' about your life, such as living arrangement, monetary situation, or course load. For example, you may have moved to a better dorm or better roommate, received an increase in financial support so you can have more fun, or dropped a course that you were really going to have trouble with." The activity item read: "Please rate the extent you have adopted some significant positive new goal or activity since the beginning of the semester, which has given you a boost since it occurred.

'Goal/activity' means something you chose to do or get involved in, which takes effort on your part. For example, you may have joined a rewarding new group, club, or sports team, decided on a major or career direction which makes it clear what to focus on, or taken on some other important new project or goal in your life."

Figure 2 reproduces a longitudinal path model that well-fit the data. As expected, both positive activity and circumstantial changes predicted increased happiness at Time 2. However, only activity changes predicted happiness at Time 3 , indicating that the earlier activity-based gains 
had been maintained, whereas the earlier circumstance-based gains had been attenuated.

Parenthetically, the two change variables correlated .34 with each other, suggesting that some overlap does indeed exist between the two categories. Again, however, only the activity change variable accounted for maintained change in well-being. These results suggest that, at least in the short-term, it is possible to increase one's well-being above the set point, and then to maintain it there.

Two other findings from this research program deserve mention. First, Sheldon and Lyubomirsky (2003) found, in a separate study using the same two change measures, that activity changes are associated with more varied experiences and less of a sense of "getting used to" (i.e., adapting to) the change, compared to circumstantial changes. This finding supports an important premise of our longitudinal model - namely, that activity changes induce more varied experiences and less hedonic adaptation, relative to circumstantial changes. Again, we believe these characteristics of activity help account for its potential long-term effect on happiness.

Second, Sheldon and Lyubomirsky found, in the longitudinal study, that competence and relatedness need-satisfaction (Deci \& Ryan, 2000; Sheldon, Elliot, Kim, \& Kasser, 2001) mediated the sustained activity effects. In other words, the reason why newly-adopted activities at Time 1 produced sustained gains in well-being at Time 3 is that participants felt more competent in their daily lives during the semester, and felt more related to others during the semester. These findings make sense, given the kinds of activity changes participants listed. Examples include: "When I first got here, my classes seemed hard and I didn't study as much as I should have. I set myself a goal to study for at least 5 hours a day and now my classes are going a lot better for me;" "I used to not ever go to church but now I am going to Campus Crusade for Christ meetings, and God is more a part of my life than He ever has been;" and "I made a goal for myself that I would get involved and spend mostly all of my free time working on homecoming for my fraternity."

In contrast, circumstantial changes tend to be more superficial, and bring less opportunity to fulfill deeper psychological needs. To illustrate, consider some typical circumstantial changes people listed: "I learned that I won't have to be in a lottery in order to get in my Broadcast 1 class (which is required)," "My roommate at the beginning of the semester was a cocaine addict. She is 
no longer my roommate," and "I was recently initiated into my fraternity. The stress level of my life has now decreased because I no longer have to worry about initiation requirements." In short, the limited relevance of circumstantial changes for psychological need-satisfaction may be another reason such changes have limited influence on well-being, in addition to the reason that people more quickly habituate to altered circumstances.

Notably, the mediational findings are consistent with "bottom-up" models of well-being, which posit that global judgments of well-being are made by summating across one's recent positive experiences. We believe that daily feelings of competence and relatedness, induced by activity, are important sources of such judgments. However, we also believe that changing one's activities can also create positive "top-down" influences on happiness. Top-down models of wellbeing propose that one's global attitudes, expectancies, or self-concept may positively color all of one's well-being judgments. Clearly, successful activity is a potentially important route to enhanced life expectancies and self-concepts - for example, the student described above, who now studies 5 hours a day and is succeeding in her classes, may now think of herself as an excellent student who can achieve whatever she aspires.

\section{Happiness-Inducing Interventions}

Recently, Lyubomirsky, Tkach, and Yelverton (2003) conducted two different happinessenhancing interventions, attempting to sustainably boost college students' well-being. This endeavor builds on earlier intervention work by Fordyce (1977, 1983), but also draws from the contemporary positive psychology tradition, and its attempt to identify essential human strengths and virtues (Seligman, 2003). Specifically, the two interventions experimented with prompting participants to practice, on a regular basis, either "random acts of kindness" (Study 1) or counting one's blessings (Study 2).

Committing random acts of kindness is a behavioral happiness-enhancing strategy that was expected to boost temporary moods and long-lasting well-being, based on prior theory and research. For example, individuals who report a greater interest in helping people, a tendency to act in a prosocial manner, or intentions to perform altruistic or courteous behaviors are more likely to rate themselves as dispositionally happy (Feingold, 1983; Lucas, 2000; Rigby \& Slee, 1993; 
Williams \& Shiaw, 1999). Although no experimental tests of the associations between happiness and generosity are available, acts of kindness can conceivably boost happiness in a variety of ways. Such acts may promote a charitable perception of other people and one's social community, a heightened sense of interdependence and cooperation, and a perception of one's good fortune. In addition, people who commit acts of kindness may begin to view themselves as generous people, as well as to feel more confident, efficacious, in control, and optimistic about their ability to help (Clark \& Isen, 1982; Cunningham, 1988). Furthermore, acts of kindness can inspire greater liking by others, as well as appreciation, gratitude, and prosocial reciprocity (Trivers, 1971), all of which are valuable in times of stress and need. Finally, acts of kindness may help satisfy a basic human need for relatedness (Baumeister \& Leary, 1995), thereby contributing to increased happiness, as in the Sheldon and Lyubomirsky (2003) study described above.

In their intervention, Lyubomirsky and colleagues asked students to perform five random acts of kindness per week, over the course of six weeks. Such acts were described as behaviors that benefit others or make others happy, typically at some cost to oneself (e.g., dropping coins into a stranger's parking meter, donating blood, helping a friend with a problem set, visiting a sick relative, or writing a thank-you note to a former teacher). A no-treatment control group simply completed the measures of well-being - first, immediately before the intervention and last, immediately after the intervention. The findings, shown in the top panel of Figure 3, support the hypothesis that a short-term happiness-enhancing activity can increase well-being. While the control group (left) experienced a reduction in happiness over the course of the 6-week period, the experimental group (right) experienced an increase.

The second intervention tested a cognitive happiness-increasing practice. Recently, Emmons and McCullough showed that practicing gratitude on a regular basis can enhance wellbeing (Emmons \& McCullough, 2003; McCullough, Kilpatrick, Emmons, \& Larson, 2001). Grateful thinking promotes the savoring of positive life experiences and situations, so that the maximum satisfaction and enjoyment is extracted from one's circumstances. As noted above, this activity may directly counteract the effects of hedonic adaptation, by helping people to distill as much appreciation from the good things in their lives as possible. In addition, the capacity to 
appreciate one's life circumstances may also be an adaptive coping strategy by which people positively reinterpret problematic life experiences, bolster coping resources, and strengthen social relationships. Finally, the practice of gratitude is incompatible with negative emotions, and thus may reduce feelings of envy, anger, or greed.

In Lyubomirsky and colleagues' second intervention, which was also of six weeks duration, students were instructed to engage in self-guided exercises involving counting their blessings either once a week or three times a week. Examples of "blessings" listed by students included "getting through my first set of midterms," "having supportive friends," "the car my dad bought me," "my parents telling me that they love me," and "AOL instant messenger." As in Study 1, control participants, by contrast, only completed the happiness assessments. The results again supported the predictions of our model - first, that short-term increases in happiness are possible and, second, that optimal timing is important. In sum, students who regularly expressed gratitude showed increases in well-being over the course of the study, relative to controls, but those increases were only evident for those students who performed the activity only once a week (see the bottom panel of Figure 3). Perhaps counting one's blessings several times a week led people to tire of the practice, finding it less fresh and meaningful over time.

The results of these two interventions are encouraging, suggesting a promising program of research that has vast applications for the possibility of increasing happiness in the larger population. Notably, however, these studies did not test the sustainability of the well-being increases for the experimental (i.e., "kindness" and "blessings") groups and did not examine the effects of key moderators of activity effects. These moderators are described below.

\section{Future Research and Recommendations for Interventions}

\section{Potential Moderators of Activity Effects}

Our theoretical model (Sheldon, Lyubomirsky, \& Schkade, 2003) goes beyond specifying three classes of determinants of happiness (i.e., set point, circumstances, and activities). It additionally makes several as-yet untested assumptions, which will be briefly considered here, as they may be relevant to the long-term task of developing maximally effective happiness interventions. We will first consider the question of how to choose a particular happiness-boosting 
activity, then the question of how such activity may be initiated, and then the question of how the activity can be maintained over time to produce a sustained increase in the chronic level of happiness. In the process, we will discuss the issue of person-strategy fit, the meaning and nature of effort, the definition and role of habits, the importance of social support, and the influence of the individual's cultural membership.

Choosing an activity: The role of person-activity fit. Not all activities will help a particular person become happier. People have enduring strengths, interests, values, and inclinations, which predispose them to benefit more from some activities than others. This general "matching" hypothesis (Harackiewicz \& Sansone, 1991; Snyder \& Cantor, 1998) is supported by much recent work showing that the positive effects of goal-attainment on subjective well-being are moderated by goal-person fit (Brunstein, Schultheiss, \& Grassman, 1998; Diener \& Fujita, 1995; Sheldon \& Elliot, 1999; Sheldon \& Kasser, 1998). It is also supported by past well-being intervention research. For example, in several studies that instructed participants to apply 14 different techniques to raise their personal happiness, the most effective happiness-increasing strategies varied greatly from one individual to another, and appeared to be determined by each participant's needs and specific areas of weakness (Fordyce, 1977, 1983).

The role of effort. We assume that performing an activity necessitates at least two different kinds of effort - first, the effort needed to initiate the activity, and second, the effort needed to actually carry out and maintain the activity. The first kind of effort refers to the difficulty of "overcoming inertia" or "getting over the hump," such that one starts doing an activity. For example, meditating in the morning, making time to work on at least one important project during the day, or dropping by the gym at the end of the day can have significant benefits, but only if one can remember to do them and overcome any obstacles to initiating them. We assume that this kind of self-regulatory effort requires considerable self-discipline and willpower to exert. Furthermore, such effort may constitute a limited resource. In Muraven and Baumeister's (2000) terms, selfregulatory will is like a "muscle," which has a limited capacity in a given unit of time, and must be used strategically in order to avoid fatigue. 
Of course, some activities will be intrinsically more appealing, and will be easier to jumpstart - indeed, this is undoubtedly one advantage of selecting an activity that fits one's personality. For example, rather than jogging around the block, a fitness-seeking wilderness-lover might instead choose to run on a trail through the woods, thereby feeling much less initial resistance to beginning the activity. As another example, rather than expressing one's gratitude and appreciation in a diary, a visually-oriented individual might instead choose to express herself through painting and a musical individual might instead choose to write a song. Such choices would enhance the intrinsic appeal of sitting down to engage in the activity.

As these examples illustrate, finding intrinsically-motivated activities may be crucial not only for one's ability to initiate the activity, but also, for one's ability to keep on doing the activity in the long term. If the activity becomes boring, then the person may stop doing it. In this light, an important factor influencing activity's effect on happiness likely concerns how one varies one's activities. For example, by shifting attention among several projects at work, by exploring new trails in the state park, or by focusing one's gratitude on different aspects of one's life, a person's activities should remain intrinsically enjoyable and conducive to many rewarding "flow" experiences (Csikszentmihalyi, 1990). Another factor may be the timing of activity; if one does the activity too often, or not often enough, or at the wrong times, then it may lose its efficacy. For example, Lyubomirsky et al. (2003) found that counting one's blessings once a week may be the optimal rate or schedule.

The role of social support. Social support is believed to be another important factor in enacting happiness changes. Following through on one's volitional intentions can be tough, and the task can be made easier if others are "in the same boat." Indeed, many groups and organizations, such as Alcoholics Anonymous or Weight-Watchers, emphasize the import of having "teammates" during one's abstinence attempts. Thus, we assume that interpersonal support can aid an individual both in initiating a potential happiness-increasing activity and in maintaining it. In addition, because social support is an important correlate of psychological well-being in its own right (e.g., Baldassare, Rosenfield, \& Rook, 1984; Henderson \& Brown, 1988), performing an 
intentional activity as a group or with the support of close others is likely to promote greater and more sustained happiness change than "bowling alone" (Putnam, 2000).

The role of habitual activity. If activities such as "maintaining an optimistic outlook about the future," "spending time on the things that matter," or "pursuing a meaningful life goal" can indeed enhance and sustain new happiness, then it would arguably be a good idea to make a habit of doing them. However, at first glance, habits appear to present a paradox for our model. By acquiring a habit, doesn't one necessarily turn a formerly conscious activity into an unconscious one, which is practiced routinely, automatically, and without variation? If so, isn't one likely to experience hedonic adaptation to that activity, such that it loses its happiness-boosting potential?

Perhaps not. However, to illustrate, we must distinguish between two different types of habits - first, the habit of regularly initiating a potentially beneficial activity, and, second, the habit of implementing it the same way every time. The first type of habit is likely to be a valuable and beneficial one, because it can help one continually "to get over the hurdle." For example, a woman might make running or yoga an automatic part of her daily routine, thus deriving considerable benefit. In contrast, the second type of habit is likely to be problematic, because it is most likely to foster boredom and ultimately lead to hedonic adaptation. For example, the woman might run the same route every day, and begin to get tired of running. To overcome this, as suggested above, people should mindfully attend to optimal timing and variety in the ways they practice an activity. For example, the woman might want to vary the route, time of day, and duration and pace of her running. This will help forestall the effects of adaptation.

The role of cultural membership. Another potential moderator of activity effects on happiness may be the norms and traditions of the culture in which the individual resides. There is little doubt that the "pursuit of happiness" is an important and well-supported element of U.S. culture. However, in cultural settings that de-emphasize individual happiness or striving, or perhaps actively disapprove of them, it may be more difficult to take action to increase one's happiness level. Alternatively, in collectivist cultures, happiness-relevant activity may merely require a somewhat different focus. In these settings, it may be more effective to act in service of others rather than acting in service of personal achievements and goals. In terms of the Sheldon and 
Lyubomirsky (2003) data described above, activities that provide relatedness need-satisfaction may be more important in such cultures than activities providing competence need-satisfaction (Sheldon, Elliot, Kim, \& Kasser, 2001). These important questions await future research.

\section{Factors Influencing Participants' Acceptance of Interventions}

The previous section concerned some potentially important dynamic factors that may influence the effect of activity on sustained well-being. In this section, we will consider some potentially important contextual factors that may influence the extent to which participants take maximal advantage of happiness-enhancing opportunities.

One factor concerns the manner in which participants are prompted to take part in the presented activity or opportunity. Self-determination theory (Deci \& Ryan, 1985, 2000) examines in detail the approaches by which teachers, coaches, bosses, and parents can best motivate their charges, focusing in particular on "autonomy support." Supporting autonomy means taking the target's perspective, providing as much choice as possible, and supplying a meaningful rationale when choice-provision is not possible. In contrast, controlling behavior involves "must" or "should" language, insensitivity to the perspective of the one being motivated, and lack of concern with providing a sense of choice to the one being motivated. This analysis suggests that when enrolling people into happiness intervention programs, it will be very important not to imply that they "have" to do it, or that they "must" or "should" become happier!

This analysis also raises important issues concerning how to properly test the happinessinducing potential of a particular program or intervention. Ideally, double-blind procedures would be used, in which neither the participant nor the experimenter is aware of the "treatment" being given, and in which the participant has no conception of the experimental hypothesis. But is this reasonable or desirable, when the intervention concerns encouraging people to take intentional action that may enhance their personal well-being? Perhaps such interventions can only work if the participant is fully aware of what the research is about. Although this possibility raises potential methodological problems concerning placebo and demand effects, such problems may be surmounted with appropriate control groups. In addition, the issues of autonomy-support and person-strategy fit suggest that participants should be given the choice of what intervention to 
enact, rather than being randomly assigned to interventions. Such self-selection procedures may once again threaten conventional methodological standards, but again, the problem may perhaps be offset by careful experimental design.

A related issue is how happiness-enhancing programs or practices should be labeled. Should their potential relation to happiness be acknowledged directly, or should they instead be simply introduced as "positive life-practices" involving "kindness," "gratitude," "physical exercise," or what have you? The latter content-based approach may be preferable, for several reasons. First, as discussed above, the explicit happiness label approach is more likely to create demand effects that may obscure whatever real changes are occurring for participants. Second, inducements like "Do you want to be happy?" might not appeal to a segment of potential participants, who might object to associations with self-help gurus and popular psychology "howto" books, or for whom the term "happiness" denotes unrealistic and wrongheaded positivity and optimism. Third, content-based (rather than happiness-based) labeling may sidestep another possible barrier to intervention efficacy - namely, that active and conscious attempts to increase happiness might backfire altogether if the person becomes too focused on this goal (i.e., "Are we having fun yet?"; Schooler, Ariely, \& Loewenstein, in press). In other words, it is probably better to be fully engaged in the activities of one's life, without frequently pausing to ask, "Am I happy?" In this case, happiness may come as a natural by-product of a life well-lived.

\section{Recommendations for Happiness}

What are the most general recommendations for increasing happiness suggested by our model? Simply, that happiness-seekers might be advised to find new activities to become engaged in - preferably activities that fit their values and interests. They should make a habit out of initiating the activity, while at the same time varying the way they implement the activity and aiming for the optimal timing of the activity. People might be advised to avoid basing their happiness on the acquisition of particular circumstances or objects (e.g., buy a luxury car, arrange for cosmetic surgery, or move to California), because they will tend to habituate to such stable factors. However, if one can remember to appreciate or actively engage with the object or circumstance (i.e., pause to savor one's new Mercedes or take advantage of the California weather), 
then stable objects and circumstances may not be stable after all, from a phenomenological perspective.

\section{Conclusion}

Two hundred and twenty-seven years ago, the American Declaration of Independence proclaimed "the pursuit of happiness" as a god-given right. Today, after decades of scientific research into subjective well-being, we still do not even know if such pursuit is possible, much less how best to effect it. Given the breadth of beneficial effects that follow from subjective well-being, for both the individual and those around him or her (Lyubomirsky, King, \& Diener, 2003), it seems vital to undertake such research. Fortunately, there are emerging reasons to believe that "the pursuit of happiness" is indeed a practical and attainable goal. In this chapter, we have described these reasons, and also presented our own model depicting the architecture of sustainable gains in happiness. We have also made a number of suggestions about what kinds of interventions and activities are expected to be most effective. Finally, we have described some important factors that are likely to influence the effectiveness of any adopted activity, such as person-activity fit, appropriate effort, positive habits, and social support. We hope these ideas will stimulate researchers to "take up the gauntlet" of better understanding longitudinal well-being. 


\section{References}

Allport, G. W. (1955). Becoming: Basic considerations for a psychology of personality. New Haven, CT: Yale University Press.

Baldassare, M., Rosenfield, S., \& Rook, K. S. (1984). The types of social relations predicting elderly well-being. Research on Aging, 6, 549-559.

Baumeister, R. F., \& Leary, M. R. (1995). The need to belong: Desire for interpersonal attachments as a fundamental human motivation. Psychological Bulletin, 117, 497-529.

Braungart, J. M., Plomin, R., DeFries, J. C., \& Fulker, D. W. (1992). Genetic influence on testerrated infant temperament as assessed by Bayley’s Infant Behavior Record: Nonadoptive and adoptive siblings and twins. Developmental Psychology, 28, 40-47.

Brickman, P., \& Campbell, D.T. (1971). Hedonic relativism and planning the good society. In M.H. Appley (Ed.), Adaptation-level theory: A symposium. New York: Academic Press.

Brickman, P., Coates, D., \& Janoff-Bulman, R. (1978). Lottery winners and accident victims: Is happiness relative? Journal of Personality and Social Psychology, 36, 917-927.

Brunstein, J. C., Schultheiss, O. C., \& Grassman, R. (1998). Personal goals and emotional wellbeing: The moderating role of motive dispositions. Journal of Personality and Social Psychology, 75, 494-508.

Clark, M. S., \& Isen, A. M. (1982). Toward understanding the relationship between feeling states and social behavior. In A. H. Hastorf \& A. M. Isen (Eds.), Cognitive social psychology (pp.71-108). New York: Elsevier/North Holland.

Costa, P. T., McCrae, R. R., \& Zonderman, A. B. (1987). Environmental and dispositional influences on well-being: Longitudinal follow-up of an American national sample. British Journal of Psychology, 78, 299-306.

Csikszentmihalyi, M. (1990). Flow: The psychology of optimal experience. New York: Harper \& Row.

Cunningham, M. R. (1988). What do you do when you're happy or blue? Mood, expectancies, and behavioral interest. Motivation and Emotion, 12, 309-331. 
Deci, E. L., \& Ryan, R. M. (1985). Intrinsic motivation and self-determination in human behavior. New York: Plenum.

Deci, E. L., \& Ryan, R. M. (2000). The "what" and "why” of goal pursuits: Human needs and the self-determination of behavior. Psychological Inquiry, 4, 227-268.

Diener, E. (1984). Subjective well-being. Psychological Bulletin, 95, 542-575.

Diener, E., \& Fujita, F. (1995). Resources, personal strivings, and subjective well-being: A nomothetic and idiographic approach. Journal of Personality and Social Psychology, 68, 926-935.

Diener, E., \& Lucas, R. E. (1999). Personality and subjective well-being. In D. Kahneman, E. Diener, \& N. Schwartz (Eds.), Well-being: The foundations of hedonic psychology (pp. 213229). New York: Russell Sage.

Diener, E., Suh, E. M., Lucas, R. E., \& Smith, H. L. (1999). Subjective well-being: Three decades of progress. Psychological Bulletin, 125, 276-302.

Emmons, R. A., \& McCullough, M. E. (2003). Counting blessings versus burdens: An experimental investigation of gratitude and subjective well-being in daily life. Journal of Personality and Social Psychology, 84, 377-389.

Fava, G. A., Rafanelli, C., Cazzaro, M., Conti, S., \& Grandi, S. (1998). Well-being therapy: A novel psychotherapeutic approach for residual symptoms of affective disorders. Psychological Medicine, 28, 475-480.

Feingold, A. (1983). Happiness, unselfishness, and popularity. Journal of Psychology, 115, 3-5. Fordyce, M. W. (1977). Development of a program to increase happiness. Journal of Counseling Psychology, 24, 511-521.

Fordyce, M. W. (1983). A program to increase happiness: Further studies. Journal of Counseling Psychology, 30, 483-498.

Frederick, S., \& Loewenstein, G. (1999). Hedonic adaptation. In D. Kahneman, E. Diener, \& N. Schwarz (Eds.), Well-being: The foundations of hedonic psychology (pp. 302-329). New York: Russell Sage Foundation. 
Gaskins, R. W. (1999). "Adding legs to a snake": A reanalysis of motivation and the pursuit of happiness from a Zen Buddhist perspective. Journal of Educational Psychology, 91, 204215.

Gillham, J. E., \& Reivich, K. J. (1999). Prevention of depressive symptoms in school children: A research update. Psychological Science, 10, 461-462.

Gloaguen, V., Cottraux, J., Cucherat, M., \& Blackburn, I. (1998). A meta-analysis of the effects of cognitive therapy in depressed patients. Journal of Affective Disorders, 49, 59-72.

Harackiewicz, J. M., \& Sansone, C. (1991). Goals and intrinsic motivation: You can get there from here. In M. L. Maehr \& P. R. Pintrich (Eds.), Advances in motivation and achievement (Vol. 7, pp. 21-49). Greenwich, CT: JAI Press.

Headey, B., \& Wearing, A. (1989). Personality, life events, and subjective well-being: Toward a dynamic equilibrium model. Journal of Personality and Social Psychology, 57, 731-739.

Henderson, A. S., \& Brown, G. W. (1988). Social support: The hypothesis and the evidence. In A. S. Henderson \& G. D. Burrows (Eds.), Handbook of social psychiatry (pp.73-85). Amsterdam: Elsevier.

Jacobson, N. S., Dobson, K. S., Truax, P. A., Addis, M. E., Koerner, K., Gollan, J. K., Gortner, E., \& Prince, S. E. (1996). A component analysis of cognitive-behavioral treatment for depression. Journal of Consulting and Clinical Psychology, 64, 295-304.

Jahoda, M. (1958). Current concepts of positive mental health. New York: Basic Books. James, H. (1909). The portrait of a lady. Boston: Houghton Mifflin.

Kahneman, D. (1999). Objective happiness. In D. Kahneman, E. Diener, \& N. Schwarz (Eds.), Well-being: The foundations of hedonic psychology (pp. 3-25). New York: Russell Sage Foundation.

Kernis, M. H, Brown, A. C., \& Brody, G. H. (2000). Fragile self-esteem in children and its associations with perceived patterns of parent-child communication. Journal of Personality, $68,225-252$. 
Langer, E. J., \& Rodin, J. (1976). The effects of choice and enhanced personal responsibility for the aged: A field experiment in an institutional setting. Journal of Personality and Social Psychology, 34, 191-198.

Lichter, S, Haye, K., \& Kammann, R. (1980). Increasing happiness through cognitive retraining. New Zealand Psychologist, 9, 57-64.

Lucas, R. E. (2000). Pleasant affect and sociability: Towards a comprehensive model of extraverted feelings and behaviors. Unpublished doctoral dissertation, Department of Psychology, University of Illinois.

Lykken, D. (2000). Happiness: The nature and nurture of joy and contentment. New York: St. Martin's Griffin.

Lykken, D., \& Tellegen, A. (1996). Happiness is a stochastic phenomenon. Psychological Science, 7, 186-189.

Lyubomirsky, S. (2001). Why are some people happier than others?: The role of cognitive and motivational processes in well-being. American Psychologist, 56, 239-249.

Lyubomirsky, S., King, L. A., \& Diener, E. (2003). Is happiness a good thing? A theory of the benefits of long-term positive affect. Manuscript submitted for publication.

Lyubomirsky, S., \& Lepper, H. S. (1999). A measure of subjective happiness: Preliminary reliability and construct validation. Social Indicators Research, 46, 137-155.

Lyubomirsky, S., Tkach, C., \& Yelverton, J. (2003). Pursuing sustained happiness through random acts of kindness and counting one's blessings: Tests of two six-week interventions. Unpublished data, Department of Psychology, University of California, Riverside.

McCrae, R. R., \& Costa, P. T. (1990). Personality in adulthood. New York: Guilford Press.

McCrae, R. R., \& Costa, P. T. (1994). The stability of personality: Observations and evaluations. Current Directions in Psychological Science, 3, 173-175.

McCullough, M. E., Kilpatrick, S. D., Emmons, R. A., \& Larson, D. B. (2001). Is gratitude a moral affect? Psychological Bulletin, 127, 249-266.

McCullough, M. E., Pargament, K. I., \& Thoresen, C. E. (Eds.) (2000). Forgiveness: Theory, research, and practice. New York, NY: The Guilford Press. 
Muraven, M., \& Baumeister, R. F. (2000). Self-regulation and depletion of limited resources: Does self-control resemble a muscle? Psychological Bulletin, 126, 247-259

Putnam, R. D. (2000). Bowling alone: The collapse and revival of American community. New York: Simon \& Schuster.

Rigby, K., \& Slee, P. T. (1993). Dimensions of interpersonal relation among Australian children and implications for psychological well-being. Journal of Social Psychology, 133, 33-42.

Schooler, J. W., Ariely, D., \& Loewenstein, G. (in press). The explicit pursuit and assessment of happiness can be self-defeating. To appear in J. Carrillo \& I. Brocas (Eds.), Psychology and economics. Oxford, Great Britain: Oxford University Press.

Scitovsky, T. (1976). The joyless economy: The psychology of human satisfaction. New York: Oxford University Press.

Seligman, M. E. P. (2003). Authentic happiness. New York: Free Press.

Seligman, M. E. P., \& Csikszentmihalyi, M. (2000). Positive psychology: An introduction. American Psychologist, 55, 5-14.

Sheldon, K. M., \& Elliot, A. J. (1999). Goal striving, need-satisfaction, and longitudinal well-being: The Self-Concordance Model. Journal of Personality and Social Psychology, 76, 482-497.

Sheldon, K. M., Elliot, A. J., Kim, Y., \& Kasser, T. (2001). What is satisfying about satisfying events? Testing 10 candidate psychological needs. Journal of Personality and Social Psychology, 80, 325-339.

Sheldon, K. M., \& Houser-Marko, L. (2001). Self-concordance, goal-attainment, and the pursuit of happiness: Can there be an upward spiral? Journal of Personality and Social Psychology, $80,152-165$.

Sheldon, K. M., \& Kasser, T. (1998). Pursuing personal goals: Skills enable progress but not all progress is beneficial. Personality and Social Psychology Bulletin, 24, 1319-1331.

Sheldon, K. M., Kasser, T., Smith, K., \& Share, T. (2002). Personal goals and psychological growth: Testing an intervention to enhance goal-attainment and personality integration. Journal of Personality, 70, 5-31. 
Sheldon, K. M., \& King, L. (2001). Why positive psychology is necessary. American Psychologist, $56,216-217$.

Sheldon, K. M., \& Lyubomirsky, S. (2003). Achieving sustainable increases in happiness: Change your actions, not your circumstances. Manuscript submitted for publication.

Sheldon, K. M., Lyubomirsky, S., \& Schkade, D. (2003). Pursuing happiness: The architecture of sustainable change. Manuscript submitted for publication.

Snyder, M., \& Cantor, N. (1998). Understanding personality and social behavior: A functionalist strategy. In D. T. Gilbert, \& S. T. Fiske (Eds.), The handbook of social psychology (Vol. 1, 4th ed.) (pp.635-679). New York: McGraw-Hill.

Stones, M. J., \& Kozma, A. (1985). Structural relationships among happiness scales: A second order factorial study. Social Indicators Research, 17, 19-28.

Suh, E. M., Diener, E., \& Fujita, F. (1996). Events and subjective well-being: Only recent events matter. Journal of Personality and Social Psychology, 70, 1091-1102.

Taylor, S. E., \& Brown, J. D. (1988). Illusion and well-being: A social psychological perspective on mental health. Psychological Bulletin, 103, 193-210.

Tellegen, A., Lykken, D. T., Bouchard, T. J., Wilcox, K. J., Segal, N. L., \& Rich, S. (1988). Personality similarity in twins reared apart and together. Journal of Personality and Social Psychology, 54, 1031-1039.

Trivers, R. (1971). The evolution of reciprocal altruism. Quarterly Review of Biology, 46, 35-57.

Tversky, A., \& Griffin, D. (1991). Endowment and contrast in judgments of well-being. In F. Strack, M. Argyle, \& N. Schwarz (Eds.), Subjective well-being: An interdisciplinary perspective (pp. 101-118). Oxford, England: Pergamon Press.

Vallacher, R. R., \& Nowak, A. (2002). The dynamical perspective in personality and social psychology. Personality and Social Psychology Review, 6, 264-273.

Williams, S., \& Shiaw, W. T. (1999). Mood and organizational citizenship behavior: The effects of positive affect on employee organizational citizenship behavior intentions. Journal of Psychology, 133, 656-668. 


\section{Author Notes}

Kennon M. Sheldon, Department of Psychology, University of Missouri, Columbia. Sonja Lyubomirsky, Department of Psychology, University of California, Riverside.

This work was supported in part by grants from the Positive Psychology Network.

Correspondence concerning this article should be addressed to Kennon M. Sheldon, Department of Psychological Sciences, 112 McAlester Hall, University of Missouri, Columbia, MO 65211; e-mail: SheldonK@missouri.edu or to Sonja Lyubomirsky, Department of Psychology, University of California, Riverside, CA 92521; e-mail: sonja@citrus.ucr.edu. 


\section{Figure Captions}

Figure 1. Three primary factors influencing the chronic happiness level.

Figure 2. Longitudinal path model predicting maintained changes in well-being.

Figure 3. Changes in well-being over the six-week intervention for Study 1 (top panel) and Study 2 (bottom panel). 


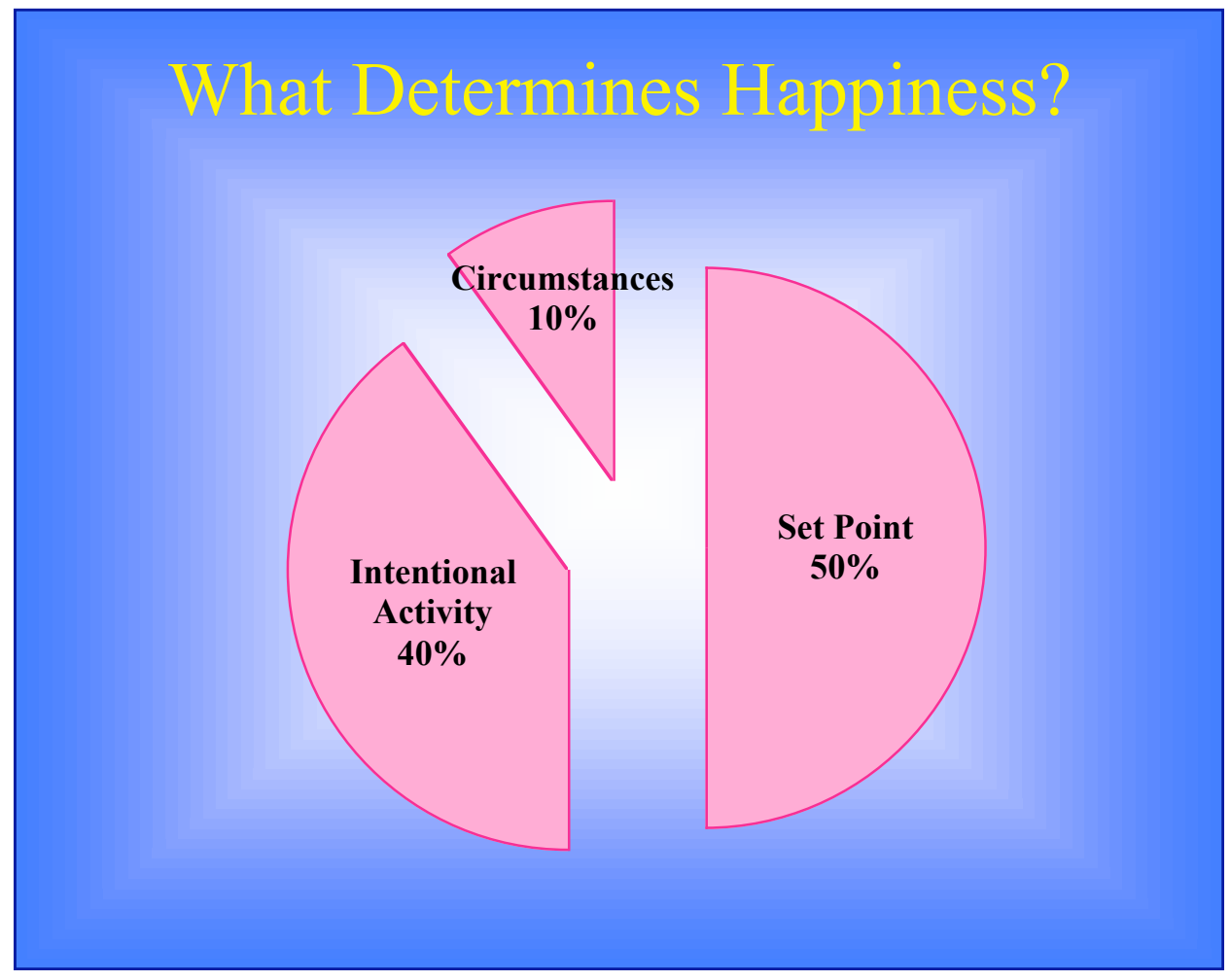




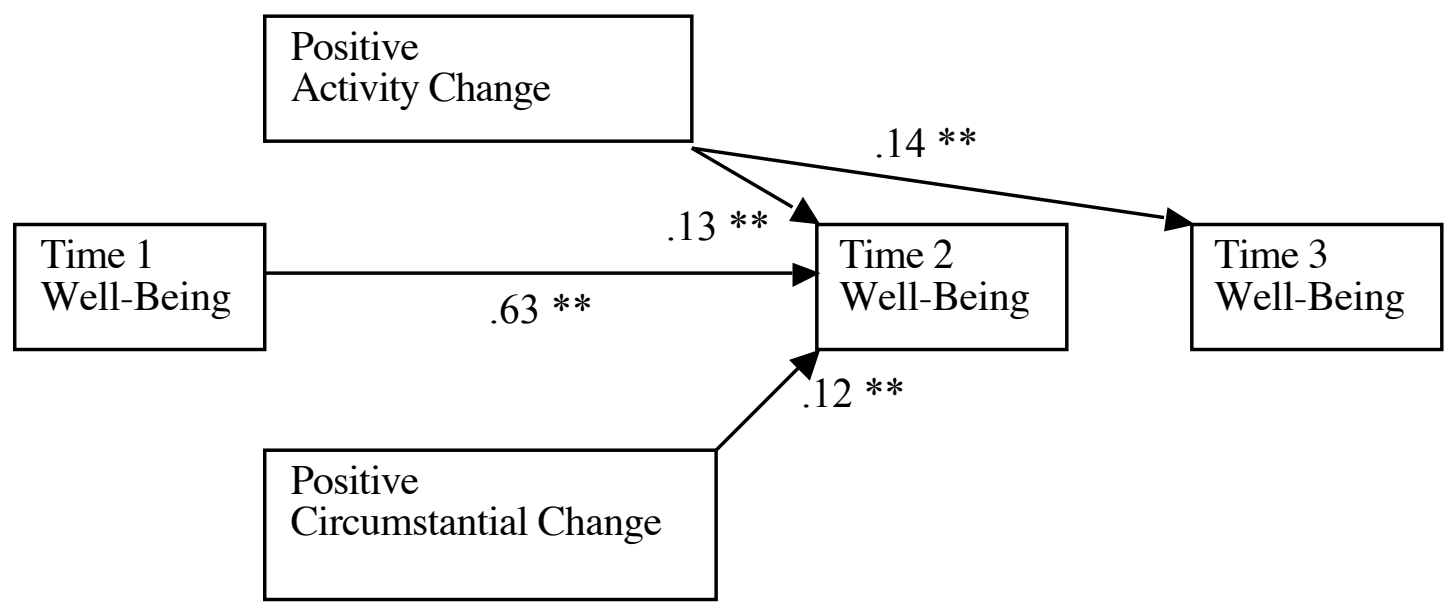



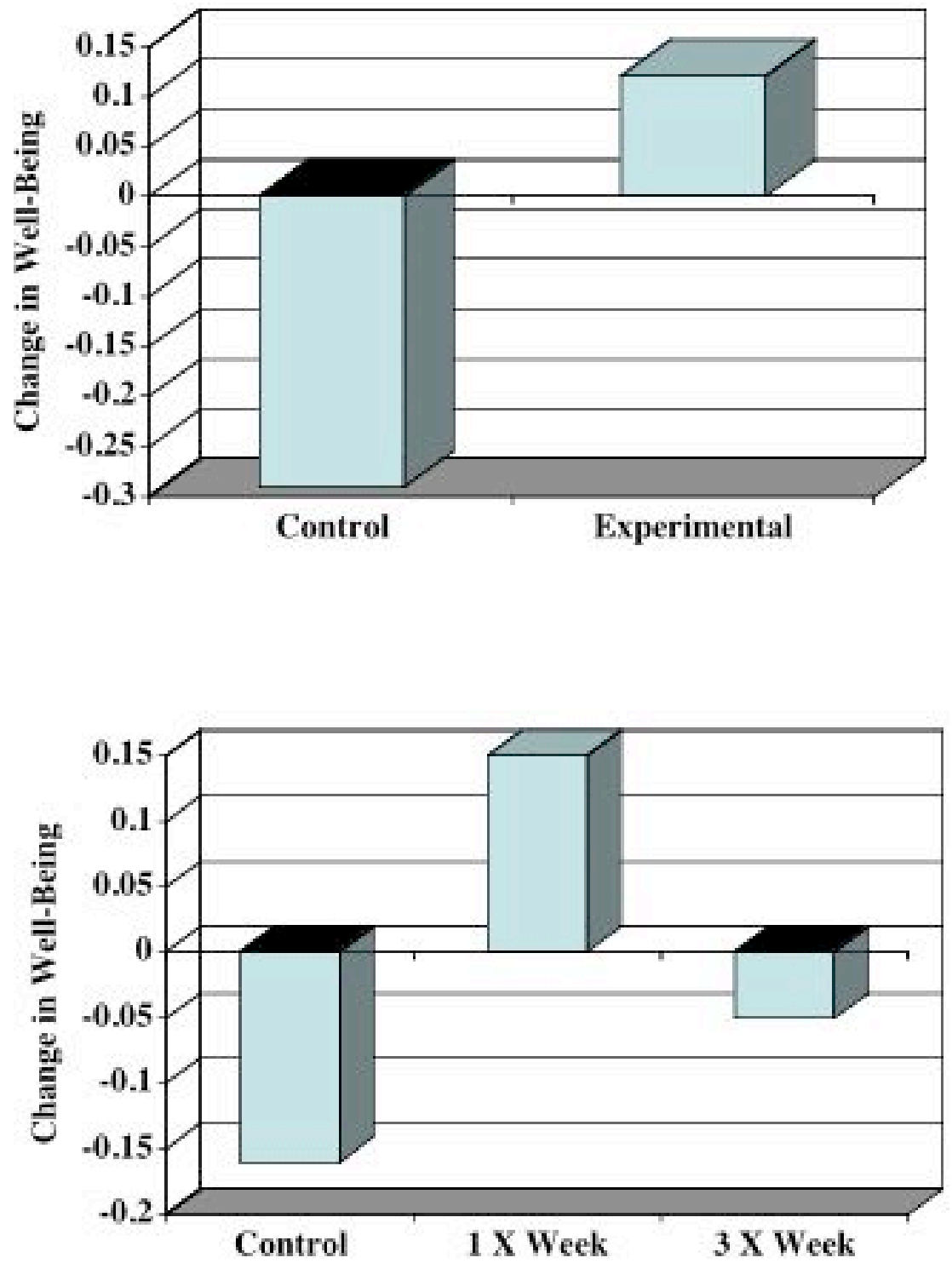